\title{
TECHNOLOGICAL SOURCES OF ECONOMIC GROWTH IN EUROPE AND THE U.S.
}

\author{
Benedetto MOLINARI ${ }^{1,2}$, José L. TORRES ${ }^{1^{*}}$ \\ ${ }^{1}$ Department of Economics, University of Málaga, Campus El Ejido, s/n, 29013 Málaga, Spain \\ ${ }^{2}$ RCEA, 75 University Ave W, N2L 3C5 Waterloo (ON), Canada
}

Received 22 February 2013; accepted 06 January 2017

\begin{abstract}
This paper assesses the role of different sources of technological change as determinants of economic growth in a group of selected OECD countries during the period 1980-2010. We consider three different sources of growth: neutral technical change associated with Total Factor Productivity, investment-specific technical change (ISTC) embodied in capital assets, and improvements in the quality of labor services generated by human capital accumulation. The contribution to growth of each of these sources is computed using two different approaches: the standard (statistical) growth accounting and the structural growth decomposition obtained from a general equilibrium growth model. We found that the effect of ISTC dominates that of neutral technology and human capital in all of the countries considered. On average, more than $50 \%$ of productivity growth is explained by ISTC. Contributions to growth from ICT and non-ICT technical change are in general of similar magnitude.
\end{abstract}

Keywords: output and productivity growth, growth accounting, investment-specific technological change, neutral technological change, human capital.

JEL Classification: $\mathrm{O} 3, \mathrm{O} 4$.

\section{Introduction}

In 2008, the worldwide financial crisis ended one of the longest periods of sustained growth in developed countries. During that period, a large number of OECD countries experienced sustained economic growth, low unemployment rates, and high levels of labor productivity. Several explanations for this golden age of the economy have been suggested by the economic literature. In particular, one of the most debated candidates was the widespread adoption in production and business practices of Information and Communication Technologies [henceforth, ICT]. The effect of ICT on growth was studied in several works, focusing both on the country leading this "technological revolution" i.e. the United States, (for instance, Jorgenson and Stiroh (2000), Jorgenson (2001), Stiroh (2002), Cummins and Violante (2002), Oliner

\footnotetext{
${ }^{\star}$ Corresponding author. E-mail: jtorres@uma.es
} 
and Sichel (2000, 2003)), and on European countries (Daveri (2002), Colecchia and Schreyer (2002), Jalava and Pohjola (2002), van Ark, Inklaar, and McGukin (2003), Timmer and van Ark (2005), among others). In general, ICT has been shown to stimulate the economic activity through different channels. First, ICT has a direct impact on GDP, as ICT industry is more productive than other industries producing traditional investment goods, an economy with a higher fraction of resources allocated to the production of ICT assets typically shows higher growth rates. Second, it has an indirect effect on the productivity of the other production factors. ICT devices are nowadays embedded in many traditional capital assets, e.g. equipment and machinery, improving their efficiency and therefore enhancing their productivity. Finally, the adoption of ICT may improve the Total Factor Productivity [henceforth, TFP] either by triggering a reorganization of the business model (Samaniego 2006), or by fostering sustainable development (Melnikas 2010).

Previous literature mainly analyzed the role of ICT without jointly considering other sources of growth, e.g. the effect of human capital accumulation on labor skills or non-ICT technical innovations. In this paper, we perform a more comprehensive analysis of the determinants of economic growth. To this end, we develop a general setup in which multiple sources of growth concur in explaining the growth rates of GDP and productivity observed in a group of selected OECD countries during the last 30 years. In the literature, economic grow this traditionally analyzed using growth accounting. This paper pursues the same approach improving upon the existing literature in three dimensions. First, we implement a new procedure to separate the contribution of technological progress in ICT assets from the one in traditional investment assets (equipment and machinery). The separation of technological progress according to its origin appears a central issue to evaluate correctly the contribution of ISTC to growth, given the markedly different evolution of ICT and nonICT technology over the last decades, and the radical effect that ICT has had on capital productivity observed since its first adoption in business practice. Second, we account for the accumulation of human capital, which is a source of growth usually neglected in growth accounting analyses. ${ }^{1}$ As a matter of fact, a large branch of literature provided evidence of the relationship between human capital, workers' skills, and labor productivity, and we show that in our data the quality of labor services significantly increased affecting the efficiency of labor services. Thus, it seems a natural choice to include the effect of human capital as an additional source of growth. Finally, we use an extended data sample (1980-2010) to assess the effect of technology on growth.

In the empirical analysis, we disentangle investment-specific technical change [henceforth, ISTC] in ICT assets (hardware, software, and communication equipment) from that in traditional capital (transport equipment, machinery, and other equipment). To this end, we construct two different time-series of quality-adjusted investment prices and we use them to identify technical change specific to each of the two types of capital. The construction of a quality-adjusted series of investment prices specific for traditional (non-ICT) assets in European countries is a side contribution of the paper. To obtain this series, we combined the information on nominal prices of investment reported in EU KLEMS with the quality-

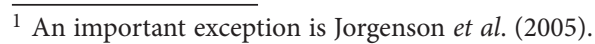


adjusted prices of investment estimated by Cummins and Violante (2002) for the U.S. These quality-adjusted prices are used to deflate EU KLEMS investment prices according to the methodology proposed by Schreyer (2002). From this strategy, we obtain quality-adjusted prices of non-ICT capital for the entire set of European countries considered. Because Cummins and Violante only reported data until 2000, we eventually apply Schreyer's procedure to extend the whole database (European countries and the U.S.) up to 2010. It is worth noting that only a subset of the countries reported in EU KLEMS has the variety of data required by this empirical strategy. Accordingly, we restrict the analysis to the following countries: Austria, Denmark, Finland, Germany, Italy, the Netherlands, Spain, Sweden, the U.K. and the U.S.

To assess the impact of the different sources of growth, we employ two alternative approaches: (i) the traditional statistical growth accounting, which is implemented using Solow's, Jorgenson's and Hulten's methods, and (ii) the equilibrium growth accounting, which is obtained by developing a neoclassical-alike growth model which replicates the key features of the data. We pursue both approaches because we take a neutral stance in the debate started in the sixties with the contributions of Solow (1957) and Jorgenson (1966) regarding the best strategy to identify the determinants of growth. Although both authors introduced the concept of embodied technical change in the neoclassical framework, Solow (1957) assumed that technical change only occurs in the production of investment goods, whereas Jorgenson (1966) assumed that technical change existed also in the production of consumption goods, and therefore in the aggregate production function of final output. ${ }^{2}$ The debate Solow-Jorgenson was recently reopened by the criticism of Greenwood, Hercowitz and Krusell (1997) to Hulten (1992), and Oulton (2007) to Greenwood and Krusell (2007). On the one hand, Greenwood and Krusell pointed out that the statistical approach has an important drawback because it cannot isolate accurately the underlying sources of capital accumulation. Since capital accumulation is affected itself by technical change, part of the observed growth rate of capital is in fact the result of investment-specific technical change, and therefore should be accounted for as ISTC and not as factor accumulation. The equilibrium approach overcomes this issue because it expresses the optimal investment policy as function of the underlying sources of growth, therefore correctly imputing the fraction of growth generated by ISTC through the indirect effect of technical change on capital accumulation. On the other hand, Oulton argued that a general equilibrium growth model with embodied technical change is just a particular case of Jorgenson's model, in which the concept of ISTC is closely related to that of total factor productivity. Besides, the statistical method is the only approach able to identify the fraction of growth generated by the accumulation of production factors, which instead is neglected in the equilibrium growth accounting because in the long run only technological progress can account for economic growth. Note that this criticism appears particularly compelling for those economies that are blatantly not on a steady state path. As far as we understand, the two approaches are complementary in what they focus on different timings. While the general equilibrium approach focuses on the long run determinants of growth, the statistical approach focuses on short run contributions. Thus, both approaches

\footnotetext{
$\overline{2}$ A review of the Solow-Jorgenson controversy can be found in Hercowitz (1998).
} 
are used to provide a full-horizon picture of economic growth. In summary, we found that the contribution of ISTC to growth dominates that of neutral technology and human capital in all of the countries considered. On average, more than $50 \%$ of productivity growth is explained by ISTC. Contributions to growth from ICT and non-ICT technical change are of similar magnitude.

The rest of the paper is organized as follows. Section 1 presents the alternative statistical growth accounting methods and the general equilibrium growth model used in the equilibrium growth accounting. Section 2 describes the data set, the calibration of the various parameters, and reports the growth accounting results. Section 3 dwells on the implications of these results and last Section concludes.

\section{Methods}

\subsection{Statistical growth accounting}

The traditional statistical growth accounting identifies the unobservable contribution of technological progress by computing the unexplained residual of GDP growth rate after controlling for the growth rates of production factors. Therefore, this method imputes economic growth either to increases in the production factors or to the development of a more efficient production technology. In the following, we employ three different versions of this approach. First, the original method developed by Solow (1956); second, the refinement of Solow's theory proposed by Jorgenson (1966); third, the subsequent refinement put forward by Hulten (1992). Jorgenson criticized Solow's method because it considers the Total Factor Productivity as the only source of technological progress thus neglecting improvements in capital efficiency generated by investment-specific technical change. In particular, he argued that Solow erroneously accounted ISTC as neutral technology, which biases the calculation of TFP. Later on, Hulten proposed a refinement of Jorgenson's approach to identify more accurately the contribution of ISTC. According to Hulten, ISTC affects the efficiency of the whole capital stock and not only that new investment goods as assumed by Jorgenson.

The three decomposition methods use the assumption of Cobb-Douglas production function, and derive the contributions to growth in terms of growth rates. In our analysis, Solow's decomposition is specified as in the original model, whereas the methods of Jorgenson and Hulten are extended to incorporate improvements in the quality of labor services. In particular, we assume that the labor aggregate is composed by worked hours multiplied by the quality of the labor force, which represents the stock of human capital embedded in workers. The original Solow's method provides a useful tool to compare the contributions of factors accumulation vs technological progress.

According to Solow's method, the (log of) actual growth rate of output $g_{Y}$ can be decomposed into:

$$
\gamma_{Y}=\underbrace{\gamma_{A}^{S}}_{\text {TFP }}+\underbrace{\sum_{i} v_{i} \gamma_{K i}}_{\text {Capital accumulation }}+\underbrace{v_{L} \gamma_{L}}_{\text {Labor accumulation }},
$$

where $\gamma_{K i}$ is the growth rate of capital $K_{i}, \gamma_{L}$ is the growth rate of worked hours $L_{t}$, and $\gamma_{A}^{S}$ measures the aggregate contribution of technological progress to output growth, i.e. Total 
Factor Productivity [henceforth, TFP], or Solow's residual. The weight $v_{i}$ is the weighted output share with respect to capital asset $i$, which is computed using the ratio of the marginal to the average product of capital, and $v_{L}$ is the weighted output share with respect to labor, which is measured using the ratio of the marginal to the average product of labor.

Turning to Jorgenson's approach, the equation that describes the decomposition of output growth in this case is:

$$
\gamma_{Y}=\underbrace{\gamma_{A}^{J}}_{\text {TFP }}+\underbrace{\sum_{i} v_{i} \gamma_{K_{i}}}_{\text {Capital accumulation }}+\underbrace{\sum_{i} z_{i} \gamma_{i}}_{\text {ISTC }}+\underbrace{v_{L} \gamma_{L}}_{\text {Labor accumulation }}+\underbrace{v_{L} \gamma_{H}}_{H C I},
$$

where $\gamma_{A}^{J}$ is the disembodied technological progress as defined by Jorgenson and $\gamma_{i}$ is the country-specific growth rate of ISTC in capital $i$. According to Jorgenson, only new investment in technologically more advanced capital goods embed ISTC, whose effect on output growth must be therefore weighted using the ratio of nominal investment in asset $i$ to nominal GDP, i.e. $z_{i}$ in equation (2). Given that human capital is embedded in labor services, weighted output share of both human capital and raw labor are the same.

Finally, the output growth decomposition according to Hulten is given by:

$$
\gamma_{Y}=\underbrace{\gamma_{A}^{U}}_{\text {TFP }}+\underbrace{\sum_{i} v_{i} \gamma_{K_{i}}}_{\text {Capital accumulation }}+\underbrace{\sum_{i} v_{i} \gamma_{i}}_{\text {ISTC }}+\underbrace{v_{l} \gamma_{L}}_{\text {Labor accumulation }}+\underbrace{v_{L} \gamma_{H}}_{H C I} .
$$

By comparing equations (2) and (3), it is straightforward to see how Hulten's method differs from Jorgenson's. While the first weights the contribution of ISTC using capital shares $v_{i}$, the second method uses investment ratios $z_{i}$. In fact, Hulten assumes that once in place technological progress pervades the whole stock of capital and not just new assets as assumed by Jorgenson. This assumption has the side consequence that the contribution of disembodied technical change, which in both methods is computed as a residual, is always smaller in Hulten's than in Jorgenson's method because investment shares are always lower than capital shares. Intuitively, Jorgenson imputes technological progress only to new vintages of capital goods, while Hulten assumes that it affects the whole capital stock. Thus, in Hulten's method ISTC shifts more heavily the production frontier, and therefore it accounts for a larger fraction of economic growth leaving less room to the contribution of TFP.

\subsection{Equilibrium growth accounting}

To implement the equilibrium growth accounting analysis, we develop a neoclassical growth model featuring three key elements: (i) the existence of different types of capital, (ii) the presence of technical change specific to every type of capital assets, and (iii) the presence of human capital enhancing the efficiency of labor services in the production function. As a result, our model combines elements of human capital accumulation models (Uzawa (1965); Lucas (1988)), with elements of the theory on investment-specific technical change (Rodríguez and Torres (2012)). In the model, the representative household allocates non-leisure time to production and learning, which is used to produce, respectively, a final good and human capital. The final good is then used for consumption and investment in physical capital, whereas learning is used to invest in human capital. Human capital is itself employed for 
two purposes: producing the final good and investing in $\mathrm{R} \& \mathrm{D}$, which in turn improves the efficiency of physical capital through investment-specific technical innovations. To replicate the categories of capital assets in EU KLEMS, the model considers three different capital inputs in the production: ICT equipment, non-ICT equipment, and structures. Each capital is associated with an idiosyncratic process of ISTC. Output is eventually produced using a combination of five productive factors: worked hours, human capital, and the three capital assets measured in efficiency units.

Household. The economy is inhabited by an infinitely lived, representative household who has time-separable preferences defined over a final good $C_{t}$ and leisure $O_{t}$. Household's preferences are represented by the following utility function:

$$
\sum_{t} \beta^{t}\left[\phi \log C_{t}+(1-\phi) \log O_{t}\right]
$$

where $\beta \in(0,1)$ is the discount factor and $\phi \in(0,1)$ is the share of consumption on total income.

Following De Jong and Ingram (2001), we assume that the household supplies two types of labor to the market: raw labor and human capital. Raw labor is sold directly in the factors market, while human capital represents the skills accumulated by the household both through formal schooling and through on-the-job training. ${ }^{3}$ Thus, non-leisure time is split between working time, i.e., the total amount of worked hours $L_{t}$, and education time $S_{t}$, which produces human capital. By normalizing to one household's total endowment of time, the time constraint is then defined as

$$
O_{t}+L_{t}+S_{t}=1
$$

The representative household's portfolio is composed by three capital assets: Information and Communication Technologies equipment (ict), Machinery and Transport equipment (nict), and Structures (str). Accordingly, the budget constraint implies that consumption and the sum of investment cannot exceed the sum of labor and capital rental income, i.e.

$$
C_{t}+\sum_{i} I_{i, t}=W_{t} H_{t} L_{t}+\sum_{i} R_{i, t} K_{i, t}
$$

where $I_{i, t}$ is investment in asset $i=\{i c t, n i c t, s t r\}, W_{t}$ is wage, $H_{t}$ is human capital, $K_{i, t}$ is physical capital, and $R_{i, t}$ is the rental price of capital. Human capital is assumed to accumulate according to the law of motion:

$$
H_{t+1}=\left(1-\delta_{H}\right) H_{t}+I_{H, t},
$$

where $I_{H, t}$ is the investment in skill formation and the depreciation parameter $\delta_{H} \in(0,1)$ reflects the aging and replacement of the population. In other words, the household has to continually train in order to maintain his stock of human capital. The novel units of human capital are formed using the following educational technology:

$$
I_{H, t}=B_{t} H_{t}^{\theta} S_{t}^{1-\theta} \text {, }
$$

\footnotetext{
3 This formulation allows assessing the impact on growth of human capital separately from that of worked hours without introducing different types of agents in the model, e.g. high-skilled vs low-skilled workers, and therefore appears particularly convenient in the light of the empirical investigation pursued in this paper.
} 
where $B_{t}$ is a exogenous stochastic shock which it is assumed to follow a first-order autoregressive process with a drift representing average growth, $\gamma_{H}$. According to equation (8), human capital is produced by combining the existing stock of human capital with the available time spent in education, and parameter $\theta \in(0,1)$ controls for the efficiency of such production. This formulation can also be interpreted as one model with successive vintages of human capital. New skills are needed to design, introduce and/or use the new, more efficient (human) capital equipment, whereas older vintages become obsolete because those skills are not required anymore. Note that as far as $\mathrm{q}$ is positive but smaller than one, expression (8) preserves the law of diminishing returns to education.

Capital holdings $K_{i, t}$ are measured in efficiency units, which depend on the idiosyncratic technological progress developed in each assets category. Symmetrically to the case of human capital, we assume that physical capital evolves according to the law of motion:

$$
K_{i, t+1}=\left(1-\delta_{i}\right) K_{i, t}+Q_{i, t} I_{i, t},
$$

where $\delta_{i}$ is the asset-specific depreciation rate and $Q_{i, t}$ is the idiosyncratic process of ISTC for $i=\{i c t, n i c t, s t r\}$. We assume that $Q_{i, t}$ follow first-order Markov processes that display average growth rates of $g_{i}$. According to equations (6) and (9), $Q_{i, t}$ represents the amount of asset $i$ than can be purchased with one unit of consumption good, i.e., the relative price of $i$. We assume that technical innovations in the production of $i$ either increase the quality of investment goods or lowers its average cost. In both cases, innovations are revealed by variations in the quality-adjusted price of investment, which therefore identify ISTC in our model. In the perspective of our analysis, this formulation is mostly convenient because it provides an empirical counterpart to $Q_{i, t}$ that is directly measurable in data, as shown in Section 2. From a theoretical point of view, we assume that human capital is employed in firms' research departments to produce ISTC and that in each period technical innovations effectively improve the quality of capital services from $Q_{i, t}$ to $e^{\gamma_{i}} Q_{i, t} \cdot{ }^{4}$ As a result, technical change is asset-specific as observed in the data. Eventually, the problem faced by the consumer is to choose a sequence $\left\{C_{t}, L_{t}, S_{t}, H_{t+1},\left(K_{i, t+1}\right)_{i}\right\}_{t=0}^{\infty}$ to maximize the utility (4)-(5), subject to the budget constraint (6), the laws of motion (7)-(9), and a set of initial conditions $\left\{Q_{i, 0}, K_{i, 0}, H_{0}\right\}$.

Firms. The production of final output requires the services of skilled labor and capital. A profit-maximizing representative firm rent capital and employ labor in perfectly competitive factor markets. Technology is given by a constant return to scale Cobb-Douglas production function,

$$
Y_{t}=A_{t}\left(H_{t} L_{t}\right)^{\alpha_{l}} \prod_{i} K_{i, t}^{\alpha_{i}}
$$

where $A_{t}$ measures neutral or disembodied technological progress to the Total Factor Productivity. We assume it evolves according to a first-order Markov process with a drift $\gamma_{A}$ representing average growth rate. Parameters $\alpha_{h}$ for $h=\{i, l\}$ represent the elasticities of substitu-

\footnotetext{
4 See Aghion and Howitt (2005) for a description of how technical innovations improve the quality of capital services.
} 
tion among production factors. We assume $\alpha_{i} \in(0,1), \alpha_{l}=1-\Sigma_{i} \alpha_{i}$ and $\sum \alpha_{h}=1$. Given the production function (10), the first order conditions of firm's costs minimization problem deliver the following demands of factors:

$$
\begin{aligned}
& W_{t}=\alpha_{l} \frac{Y_{t}}{H_{t} L_{t}} ; \\
& R_{i, t}=\alpha_{i} \frac{Y_{t}}{K_{i, t}},
\end{aligned}
$$

for $i=\{i c t, n i c t, s t r\}$. Equations (12)-(13) state that firm hires capital and skilled labor until the marginal contribution of each factor equates its competitive rental price.

Equilibrium. A standard market clearing condition is assumed to close the model. Output is used to consume and investment in three types of capital assets, and all variables are measured in units of consumption. The market clearing condition therefore is,

$$
Y_{t}=C_{t}+\sum_{i} I_{i, t}
$$

The equilibrium outcome for this model economy is then characterized by the system of equations (7)-(12) plus the following first-order conditions of household's problem of utility maximization:

$$
\begin{gathered}
\frac{1-\phi}{\phi} C_{t}=H_{t} W_{t} O_{t} \\
\frac{(1-\phi)}{(1-\theta)} \frac{S_{t}}{O_{t} I_{H, t}}=\beta \phi\left[\frac{W_{t+1} L_{t+1}}{C_{t+1}}\right]+\beta(1-\phi)\left[\frac{S_{t}}{H_{t+1}} \frac{\left(1-\delta_{H}\right) H_{t+1}+\theta I_{H, t+1}}{O_{t}(1-\theta) I_{H, t}}\right] \\
\frac{C_{t+1}}{C_{t}}=\beta\left[\frac{Q_{i, t}}{Q_{i, t+1}}\left(1-\delta_{i}+Q_{i, t+1} R_{i, t+1}\right)\right]
\end{gathered}
$$

for $i=\{i c t, n i c t, s t r\}$. Equation (14) is the standard intratemporal condition that equates the marginal rate of substitution between consumption and leisure to the opportunity cost of one additional unit of leisure. Equation (15) is instead the intertemporal condition that equates the marginal cost of human capital to the discounted marginal benefit of human capital. Finally, the group of equations (16) display the usual Euler-equations in which the marginal cost of each capital asset is equated to its discounted expected marginal benefit.

The balanced growth path. We restrict out attention to equilibria that exhibit a balanced growth path in which all variables grow at constant rates. Specifically, output, consumption, and investment grow at the same rate $\gamma_{y}{ }^{5}$ whereas worked hours grow at the same rate of the population, which is normalized to zero. Note that in this model the leisure/working choices of the household affect the growth rate of the economy, $\gamma_{y}$, through the effect of learning on human capital. The growth rates of TFP, HCI and ISTC are exogenously determined and in

\footnotetext{
$\overline{5}$ In the following, we define low case variables as the log of upper case variables, i.e. $x_{t}=\log X_{t}$.
} 
next section we make use of EU KLEMS data to calibrate them. Finally, the balanced growth rate of capital $K_{i, t}$ differs from $g_{y}$ because it also depends on the growth rate of idiosyncratic technical change. Given the above conditions, the balanced growth rate of output in terms of exogenous measurable variables can be empirically measured using the following equation:

$$
\gamma_{y}=\underbrace{\gamma_{A}^{1 / \alpha_{l}}}_{T F P} \cdot \underbrace{\prod_{i} \gamma_{i}^{\alpha_{i} / \alpha_{l}}}_{I S T C} \cdot \underbrace{\gamma_{H}}_{H C I} .
$$

Expression (18) states that the long run growth rate of output can be decomposed into a combination of (i) the growth rate of neutral technology, (ii) the growth rates of ISTC, (iii) the growth rate of HCI. Note that the assumption of zero growth of population implies that in the long run the growth rate of output coincides with the growth rate of labor productivity, i.e. $\gamma_{y / l}=\gamma_{y}$. Thus, the model predicts that only technological progress explains the growth rate of output in the long run, which is the most remarkable difference between statistical and equilibrium growth accounting.

\section{Results}

\subsection{Data}

To implement the growth accounting methods presented in previous section, we collect EU KLEMS data on: nominal output, compensations of productive factors, amount and quality of labor services, and nominal investment in several physical capital assets. The series of specific assets investment are included in three categories of capital: (i) Information and Communication Technologies (including hardware and office equipment, communication equipment, and software), (ii) traditional equipment (including transport equipment, machinery, and other equipment), and (iii) structures. Data on investment are then used to construct the corresponding asset-specific stock of capital using the permanent inventory method. The full set of data is not available for all countries listed in EU KLEMS, and therefore the analysis is restricted to the following countries: Austria, Denmark, Finland, Germany, Italy, the Netherlands, Spain, Sweden, the U.K., and the U.S.

Table 1. Average Annual Growth Rates, 1980-2010

\begin{tabular}{|l|c|c|c|c|c|c|c|c|c|c|}
\hline & AUT & DEN & FIN & GER & ITA & NLD & SPA & SWE & U.K. & U.S. \\
\hline Variables \\
\hline \multirow{2}{*}{ GDP } & 2.57 & 2.08 & 2.49 & 2.00 & 2.01 & 1.83 & 2.93 & 2.11 & 2.01 & 2.59 \\
\cline { 2 - 14 } & $(1.81)$ & $(2.35)$ & $(3.61)$ & $(2.43)$ & $(2.25)$ & $(2.50)$ & $(2.36)$ & $(2.52)$ & $(2.53)$ & $(2.22)$ \\
\hline \multirow{2}{*}{ Productivity } & 2.28 & 1.88 & 2.62 & 2.14 & 1.59 & 0.96 & 2.05 & 1.88 & 1.79 & 1.60 \\
\cline { 2 - 13 } & $(1.44)$ & $(1.12)$ & $(3.63)$ & $(1.67)$ & $(1.49)$ & $(2.19)$ & $(3.11)$ & $(3.22)$ & $(3.01)$ & $(2.62)$ \\
\hline \multirow{3}{*}{ Hours } & 0.29 & 0.20 & -0.13 & -0.14 & 0.42 & 0.87 & 0.88 & 0.23 & 0.22 & 0.99 \\
\hline \multirow{2}{*}{ Capital } & $1.21)$ & $(1.81)$ & $(2.58)$ & $(1.07)$ & $(1.07)$ & $(1.56)$ & $(3.06)$ & $(1.77)$ & $(2.05)$ & $(1.73)$ \\
\cline { 2 - 12 } & 1.80 & 1.00 & 2.36 & 1.99 & 1.88 & 1.89 & 3.59 & 2.54 & 2.67 & 3.09 \\
\hline & $(0.45)$ & $(1.15)$ & $(1.37)$ & $(0.82)$ & $(0.56)$ & $(0.65)$ & $(1.15)$ & $(0.82)$ & $(1.19)$ & $(0.91)$ \\
\hline
\end{tabular}


Table 1 reports the average annual growth rates of GDP, labor productivity, and factors accumulation during the period 1980-2010. Standard deviations (in parenthesis) are used to assess the volatility of each series. As Table 1 illustrates, the average growth rate of real GDP has been roughly similar across countries albeit there are some important differences between the maximum (approximately $3 \%$ in Spain) and the minimum (1.8\% in the Netherlands). The process of growth convergence following the inception of democracy in Spain is fully included in our sample and this clearly upward biases the figure. As a matter of fact, the best economic performance excluding Spain is that of the U.S. However, EU KLEMS data reveal that technological innovations is just one side of the story explaining economic growth in the U.S. being the accumulation rate of worked hours the other key factor. In fact, when controlling for the effect of labor accumulation ${ }^{6}$ we find that Finland and not the U.S. is the country that experienced the best economic performance during the considered period (average growth rate of 2.6\%), followed by Austria, which experienced almost the same growth of GDP than the U.S. but with a much smaller labor accumulation. The Netherlands is the country experiencing the lowest economic performance with a growth rate of labor productivity equal to approximately $1 \%$. On average, we find no striking differences between European economies and the U.S. The average productivity growth has been $1.6 \%$ in the U.S. and approximately $2 \%$ in Europe, even though some European countries as Italy, Spain, and the Netherlands showed significantly lower growth rates of labor productivity since mid-1990s. In general, the growth rate of GDP is always higher than the one of labor productivity except in the cases of Germany and Finland that experienced negative rates of labor accumulation. Also, the growth rate of GDP is less volatile across countries than the one of labor productivity. A brief comparison between lines 1 and 3 clarifies that this fact is due to the higher variability of worked hours with respect to GDP.

Table 2. Average Annual Growth Rates, 1980-2010

\begin{tabular}{|l|c|c|c|c|c|c|c|c|c|c|}
\hline & AUT & DEN & FIN & GER & ITA & NLD & SPA & SWE & U.K. & U.S. \\
\hline Technology \\
\hline \multirow{2}{*}{ ISTC } & 3.11 & 3.10 & 2.88 & 4.48 & 2.74 & 2.37 & 3.25 & 2.92 & 2.39 & 3.56 \\
\cline { 2 - 13 } & $(3.23)$ & $(4.01)$ & $(2.85)$ & $(2.06)$ & $(2.70)$ & $(3.78)$ & $(3.02)$ & $(1.24)$ & $(3.81)$ & $(2.05)$ \\
\hline \multirow{2}{*}{ HCI } & 0.45 & 0.46 & 0.86 & 0.37 & 0.31 & 0.28 & 0.86 & 0.29 & 0.43 & 0.30 \\
\cline { 2 - 12 } & $(1.44)$ & $(1.12)$ & $(3.63)$ & $(1.67)$ & $(1.49)$ & $(2.19)$ & $(3.11)$ & $(3.22)$ & $(3.11)$ & $(2.62)$ \\
\hline Labor share & 0.67 & 0.68 & 0.69 & 0.67 & 0.66 & 0.66 & 0.64 & 0.68 & 0.72 & 0.64 \\
\hline
\end{tabular}

Table 2 reports the average annual growth rates of technological and human capital progress. As mentioned in the Introduction, we treat changes in the quality of labor services symmetrically to changes in the efficiency of capital services and, accordingly, they are accounted for as embodied labor-specific progress. Last line of Table 2 reports the average labor-income share in each country, which provides a first approximation measure of the relative impact

\footnotetext{
6 To control for the worked hours on growth, we use the growth rates of production per worked hour as alternative indicator of growth. This measure of labor productivity is computed as the ratio of GDP over total worked hours, $\frac{Y}{L}$. Thus, its growth rate is : $\gamma_{y / l}=\gamma_{y}-\gamma_{l}$.
} 
of technological and human capital progress on production. Labor-income share ranges in the interval $[0.64,0.72]^{7}$ implying that increases in labor quality have an effect on production twice as big as technical innovations. In other words, any base point increase in HCI generates double growth with respect to a base point increase in ISTC, which underlines the importance of this source of economic growth.

The index of Human Capital Improvement (HCI) used in our analysis is constructed by employing the Jorgenson, Gollop and Fraumeni (1987) approach. EU KLEMS data report several characteristics on the composition of labor force, namely, workers' educational attainment (low, medium, high), age (15-19, 30-49, 50 and over), industrial sector of employment, gender (male, female). The HCI index measures changes in the quality of labor services assigning higher values to more educated and more experienced workers. By showing an average annual growth rate equal to $0.86 \%$, Finland and Spain stand well above the other countries, whose HCI growth rates range between $0.28 \%$ and $0.46 \%$. The result of Finland is not surprising given the large amount of resources that the country invests in education and the consequent outcome of Finnish schools in international student assessments (e.g. PISA survey). The case of Spain is less intuitive and is possibly explained by the convergence process of the Spanish economy, which overlaps with the considered sample. During the period 1980-2010, Spain pursued the opening up of its economy, became a member of the European Community (EC) and started a process of liberalization of the labor market. Schooling dropouts passed from $70 \%$ to $30 \%$ and college graduates almost doubled. The stock of human capital embedded in workers rapidly rose from initial low levels to European standards. Such a rapid improvement in the level of human capital is likely to be the key factor explaining the observed increase in labor services quality. As a matter of fact, the growth rates of HCI in Spain went from $0.3 \%$ in the 1980s, when the converge process was just at the beginnings, to $1.5 \%$ during the 1990 s, i.e., at the peak of the convergence process, and reverted back to $0.7 \%$ in the $2000 \mathrm{~s}$, when convergence was almost fully attained.

The series of ISTC reported in Table 2 is obtained using quality-adjusted relative prices of investment in the different asset categories. Following Greenwood et al. (1997), we divide EU KLEMS raw data on investment prices by the price of consumption goods to wash out (i) non-asset-specific innovations that improve capital efficiency in all production sectors (neutral technical change in the terminology of this paper) and (ii) aggregate demand shocks. ${ }^{8}$ Because EU KLEMS only reports data on quality-adjusted prices for ICT assets but not for traditional assets (non-ICT), we combine these data with the series of quality-adjusted price of equipment and machinery provided by Cummins and Violante (2002) for the US. Using a Törnqvist index weighted with nominal investment shares, these data are then used to build a U.S. category-specific annual deflator index, $q_{i, t}^{U S}$. That is, we use one index for each asset category considered. Equivalent harmonized deflators for European countries are finally obtained by applying the Schreyer's (2002) methodology to U.S. data. ISTC are finally

\footnotetext{
7 The statistics from EU KLEMS are in line with the evidence provided in the literature on the capital-income share, e.g. Gollin (2002), which in our data ranges in the interval $[0.28,0.36]$.

8 Because the production of consumption goods is itself affected by neutral technical change and aggregate demand shocks, the quality-adjusted relative price of investment can be used to correctly unravel the process of technical change specific to investment assets.
} 
obtained using the expression $Q_{i, t}^{j}=P C_{t} / q_{i, t}^{j}$ where $j$ denotes the country, $P C_{t}$ is the price index for consumption of non durable goods and services less housing, and $q_{i, t}^{j}$ are qualityadjusted price indexes, which represents the amount of capital that can be purchased by one unit of output at time $t$. We interpret an increase of $Q_{i, t}^{j}$ as a positive technology innovation that reduces the average cost of production of investment good $i$ expressed in units of consumption good. We assume that the structures are not subject to efficiency improvements from ISTC. That is, $Q_{s t r, t}^{j}=1$ by construction in our analysis. ${ }^{9}$ The in-sample average growth rates of ISTC reveal that technical change grew more rapidly and less homogeneously across countries than HCI. The highest annual growth rate is observed in Germany, almost $4.5 \%$ per year, followed by U.S. (3.56\%). All of the other countries have an annual growth rate ranging between $2.3 \%$ and $3.2 \%$. Also, the volatility of ISTC across countries is more than double than that of $\mathrm{HCI}$, even when adjusting for the volatility of the corresponding factor. ${ }^{10}$

\subsection{Calibration}

In the growth accounting equations, we calibrate country-specific parameters by matching first order moments of EU KLEMS data. Specifically, we calibrate the elasticities of output with respect to capital and labor using for each factor the ratio of marginal over average product. According to national accounting rules and under the hypothesis of perfectly competitive factor markets, it can be showed that these elasticities coincide with the cost share per factor. Following the recommendations of the OECD (2001), we construct the cost shares of capital using the concept of capital services, which are the productive services embedded in the stock of capital. This concept of productive capital is interpreted as a volume index of capital services and is represented using the following expression:

$$
V C S_{i t}=\mu_{i t} K_{i t},
$$

where $\mu_{i t}$ is the nominal usage cost of capital. Denoting $R E_{t}$ the remuneration of employees, the cost shares are then given by the following expressions:

$$
v_{i, t}=\frac{V C S_{i t}}{R E_{t}+\sum_{i} V C S_{i t}} .
$$

For calibration purposes, we use the average values of cost shares over the period 19802010 as estimators for the weights $v_{i}$. The labor cost share is then obtained residually using the constant return to scale condition, i.e. $v_{l}=1-\Sigma_{i} v_{i}$. Finally, we calibrate the coefficients a's by exploiting the steady state relationships of the model, i.e. $\alpha_{i}=\frac{R_{i} K_{i}}{Y}$, and therefore setting $\alpha_{i}=v_{i}$. Consistently, we calibrate $\alpha_{l}=v_{l}$.

Table 3 reports the cost shares of capital together with those of investment, which are used as the weights of ISTC in Hulten's approach. Denmark and Sweden are the only European countries whose share of ICT appears as large as the one of U.S. - approximately $6 \%$

\footnotetext{
9 We follow the literature on ISTC, in which structures are typically used as the benchmark capital that is not affected by technical change. Gort, Greenwood and Rupert (1999), however, estimated that NIPA prices for nonresidential structures should be quality-adjusted by a $1 \%$ on annual basis.

10 The relative volatilities are computed as $\sigma_{I S T C_{i}}^{j} / \sigma_{K_{i}}^{j}$ and $\sigma_{H C I_{i}}^{j} / \sigma_{L_{i}}^{j}$.
} 
of GDP -, which is considered the leading country in this technology. All other countries lagged far beyond U.S. not only as stock of ICT over GDP, but also as investment shares thus showing no process of convergence. The countries where investment in ICT is the lowest are Austria and Italy (2\% per year), which are also the countries with the lowest stock of ICT capital as share of GDP (below 4\%).

Table 3. Investment and capital income shares, 1980-2010

\begin{tabular}{|l|c|c|c|c|c|c|c|c|c|c|}
\hline & AUT & DEN & FIN & GER & ITA & NLD & SPA & SWE & U.K. & U.S. \\
\hline Capital income shares $\left(\boldsymbol{v}_{\boldsymbol{i}}\right)$ \\
\hline Total capital & 0.331 & 0.317 & 0.315 & 0.328 & 0.334 & 0.333 & 0.365 & 0.320 & 0.279 & 0.354 \\
\hline ICT capital & 0.035 & 0.052 & 0.042 & 0.050 & 0.035 & 0.041 & 0.047 & 0.063 & 0.045 & 0.059 \\
\hline non-ICT cap & 0.122 & 0.109 & 0.138 & 0.152 & 0.169 & 0.149 & 0.134 & 0.138 & 0.121 & 0.156 \\
\hline Structures & 0.174 & 0.156 & 0.135 & 0.127 & 0.129 & 0.143 & 0.184 & 0.119 & 0.113 & 0.139 \\
\hline Investment shares $\left(\boldsymbol{z}_{\boldsymbol{i}}\right)$ \\
\hline Total capital & 0.188 & 0.172 & 0.189 & 0.161 & 0.177 & 0.171 & 0.178 & 0.178 & 0.151 & 0.143 \\
\hline ICT capital & 0.019 & 0.033 & 0.025 & 0.024 & 0.021 & 0.025 & 0.024 & 0.039 & 0.028 & 0.031 \\
\hline non-ICT cap & 0.086 & 0.076 & 0.079 & 0.074 & 0.092 & 0.078 & 0.065 & 0.086 & 0.068 & 0.057 \\
\hline Structures & 0.082 & 0.064 & 0.086 & 0.063 & 0.065 & 0.067 & 0.089 & 0.053 & 0.055 & 0.055 \\
\hline
\end{tabular}

Two final caveats are worth emphasizing about previous analysis. First, because capital shares are always higher than investment shares, then we expect Hulten's method to assign higher contributions of ISTC to growth than Jorgenson's. Second, as long as capital is measured in efficiency units, several authors recommend physical rather than economic depreciation rates to implement the permanent inventory method (see Cummins and Violante (2002) and references therein). In accordance with this prescription, we calculate investmentspecific depreciation rates of physical capital using the ratio of the capital stock over the gross formation of fixed capital, whose estimates are reported in EU KLEMS, eventually adjusting it with the average growth rate of ISTC. The procedure is repeated for all capital categories and all of the considered countries. Structures are always the assets with the slowest depreciation rate (approximately $2.8 \%$ on annual basis), while ICT is the ones with the fastest depreciation rate. In general, the depreciation rates computed using EU KLEMS data are in line with the conventional knowledge about the life-cycle of the selected investment assets. According to our calculations, software license fully depreciate in approximately two years, whereas machineries are operational for five to ten years and industrial plants for twenty to thirty years.

\subsection{Results of the statistical growth accounting}

Table 4 provides the decomposition of GDP growth obtained using Solow's method, which is useful to compare the contributions of factors accumulation vs technological progress. A clear-cut separation among three groups of countries unravels from the analysis. Austria, Denmark, Finland and Germany belong to the first group, whose growth is explained for $20-30 \%$ by inputs accumulation and for $70-80 \%$ by technological progress. Italy, Sweden 
Table 4. Solow's method. GDP Growth Decomposition, 1980-2010

\begin{tabular}{|l|c|c|c|c|c|c|c|c|c|c|}
\hline & AUT & DEN & FIN & GER & ITA & NLD & SPA & SWE & U.K. & U.S. \\
\hline GDP Growth & 2.57 & 2.08 & 2.49 & 2.00 & 2.01 & 1.83 & 2.93 & 2.11 & 2.01 & 2.59 \\
\hline Contribution & 1.78 & 1.63 & 1.84 & 1.44 & 1.10 & 0.62 & 1.06 & 1.14 & 1.11 & 0.86 \\
\hline TFP & 0.59 & 0.32 & 0.74 & 0.65 & 0.63 & 0.63 & 1.31 & 0.81 & 0.74 & 1.09 \\
\hline Capital & 0.19 & 0.14 & -0.09 & -0.09 & 0.28 & 0.58 & 0.56 & 0.16 & 0.16 & 0.64 \\
\hline Labor & 69.3 & 78.2 & 73.7 & 72.1 & 54.8 & 34.0 & 36.2 & 54.1 & 55.1 & 33.1 \\
\hline Decomposition (\%) \\
\hline TFP & 23.1 & 15.2 & 29.9 & 32.6 & 31.3 & 34.3 & 44.7 & 38.5 & 37.0 & 42.2 \\
\hline Capital & 7.5 & 6.6 & -3.6 & -4.7 & 13.9 & 31.7 & 19.1 & 7.4 & 7.9 & 24.7 \\
\hline Labor & 69.3 & 78.2 & 73.7 & 72.1 & 54.8 & 34.0 & 36.2 & 54.1 & 55.1 & 33.1 \\
\hline $\begin{array}{l}\text { Technological } \\
\text { progress }\end{array}$ & 30.7 & 21.8 & 26.3 & 27.9 & 45.2 & 66.0 & 63.8 & 45.9 & 44.9 & 66.9 \\
\hline Input accumulation
\end{tabular}

and the U.K. belong to the second group, where input accumulation explains approximately $45 \%$ of output growth while technical change explains the remaining $55 \%$. Finally, the Netherlands, Spain and the U.S. constitute the third group whose output growth is explained for $60-70 \%$ by inputs accumulation and $30-40 \%$ by technological progress. A closer inspection to the data also reveals that the predominant role of factors accumulation in the third group is mainly determined by the accumulation of labor, which is significantly higher in these three countries than in the others. More in details, the increase in worked hours contributed to growth with more than 0.5 percentage points in the Netherlands, Spain and the U.S., i.e., from $20 \%$ to $30 \%$ of total growth. In all of the other countries, the contribution of labor accumulation reached significantly lower levels - approximately 7\% of GDP growth - and in the cases of Germany and Finland, where worked hours diminished during the considered period, labor accumulation actually contributed negatively to growth. Interestingly, note that labor accumulation turns out to be a valid indicator of the growth-type occurring in a country. High rates of labor accumulation always correspond to a growth-type based on factors accumulation, whereas the same is not true for capital, as apparent by comparing the cases of Sweden and U.K. with that of the Netherland. In general, we find that the contribution of capital accumulation in absolute terms is always larger than the one of labor accumulation and, in particular, Spain and the U.S. are the two countries in which capital contributes the most, i.e., more than 1 percentage point to annual GDP growth. Although these two countries have different economies and industrial systems, they both experienced a large countrywide real-estate bubble. The over-investments in residential structures behind the bubble is most likely the key factor explaining the high growth rate of capital accumulation. In the other countries, the contribution of capital accumulation to the growth rate of GDP ranges from 0.32 to 0.81 percentage points.

Table 5 provides a closer inspection to the role of technology by reporting the growth decomposition according to Jorgenson's method. As expected, in each country TFP is significantly lower than the corresponding Solow's residual. In particular, the highest value of 
Table 5. Jorgenson's method. GDP Growth Decomposition, 1980-2010

\begin{tabular}{|l|c|c|c|c|c|c|c|c|c|c|}
\hline & AUT & DEN & FIN & GER & ITA & NLD & SPA & SWE & U.K. & U.S. \\
\hline GDP growth & 2.57 & 2.08 & 2.49 & 2.00 & 2.01 & 1.83 & 2.93 & 2.11 & 2.01 & 2.59 \\
\hline Contribution \\
\hline TFP & 0.90 & 0.63 & 0.73 & 0.38 & 0.61 & -0.11 & -0.03 & 0.32 & 0.30 & 0.11 \\
\hline Capital & 0.59 & 0.32 & 0.74 & 0.65 & 0.63 & 0.63 & 1.31 & 0.81 & 0.74 & 1.09 \\
\hline ISTC (a+b) & 0.58 & 0.67 & 0.50 & 0.59 & 0.52 & 0.53 & 0.52 & 0.61 & 0.50 & 0.54 \\
\hline ICT (a) & 0.24 & 0.39 & 0.24 & 0.22 & 0.28 & 0.27 & 0.27 & 0.33 & 0.28 & 0.31 \\
\hline Non-ICT (b) & 0.34 & 0.28 & 0.26 & 0.30 & 0.32 & 0.26 & 0.25 & 0.28 & 0.22 & 0.22 \\
\hline Labor & 0.19 & 0.14 & -0.09 & -0.09 & 0.28 & 0.58 & 0.56 & 0.16 & 0.16 & 0.64 \\
\hline HCI & 0.31 & 0.32 & 0.60 & 0.24 & 0.20 & 0.19 & 0.57 & 0.21 & 0.31 & 0.21 \\
\hline Decomposition & $(\%)$ & & & & & & & \\
\hline TFP & 34.9 & 30.3 & 29.3 & 18.9 & 30.1 & -5.7 & -1.0 & 15.2 & 14.8 & 4.4 \\
\hline Capital & 23.1 & 15.2 & 29.9 & 32.6 & 31.3 & 34.3 & 44.7 & 38.5 & 37.0 & 42.2 \\
\hline ISTC (a+b) & 22.4 & 32.4 & 20.2 & 29.7 & 26.1 & 29.1 & 17.9 & 28.9 & 24.8 & 20.8 \\
\hline ICT (a) & 9.2 & 18.9 & 9.74 & 11.0 & 13.7 & 14.8 & 9.4 & 15.6 & 14.1 & 12.1 \\
\hline Non-ICT (b) & 13.2 & 13.5 & 10.5 & 15.2 & 15.8 & 14.4 & 8.5 & 13.3 & 10.7 & 8.7 \\
\hline Labor & 7.5 & 6.63 & -3.6 & -4.7 & $13 . .9$ & 31.7 & 19.1 & 7.4 & 7.9 & 24.7 \\
\hline HCI & 12.0 & 15.4 & 24.2 & 12.1 & 9.9 & 10.6 & 19.3 & 10.0 & 15.4 & 8.0 \\
\hline
\end{tabular}

TFP is in Austria, whereas it lowers up to negative values in Spain and the Netherlands. The contribution of ISTC to growth appears relatively similar across countries, generating approximately 0.5 percentage point of GDP growth on annual basis, i.e., 20-30\% of overall growth during the considered period. Denmark, Sweden and Germany are the countries that innovate the most in terms of ISTC, but only in Germany investment-specific innovations in traditional (non-ICT) capital assets outweigh innovations in ICT. Finland and the U.K. are the countries where ISTC contributed the less. The case of Finland is especially instructive because it clarifies that does not exist a Nordic-countries fixed effect on technological progress. In fact, while TFP is the main determinant of economic growth in Finland, in Denmark and Sweden GDP growth is mainly based on ISTC. Regarding the U.K., the low contribution of ISTC is possibly explained by the slow expansion of R\&D in this country, as firstly noted by Frantzen (2000) and later confirmed by Coe, Helpman and Hoffmaister (2008). Turning to the effect of human capital on GDP growth, the contribution of HCI reaches its maximum value in Finland and Spain yielding, respectively, 0.60 and 0.57 percentage points of growth, whereas it contributes with approximately 0.3 points to growth in Austria, Denmark and the U.K. and approximately 0.2 points in the other countries.

Finally, Table 6 reports the decomposition of GDP growth achieved using Hulten's method. Results are broadly in line with the evidence obtained using Jorgenson's method with few notable differences. The contribution of ISTC is now significantly higher in all of the countries considered - between 0.86 and 1.23 percentage points of GDP growth - thus entailing a contribution to GDP growth of around $35-60 \%$ of total growth during the considered 
period. As a result, TFP computed using Hulten's method is fairly lower than the one of Jorgenson's and, in fact, it turns negative in seven out of ten countries. Austria maintains the highest contribution of TFP to growth, but the lowest switches from the Netherlands to the U.S. indicating that the difference between investment and capital shares are more marked in this country.

Table 6. Hulten's method. GDP Growth Decomposition, 1980-2010

\begin{tabular}{|l|c|c|c|c|c|c|c|c|c|c|}
\hline & AUT & DEN & FIN & GER & ITA & NLD & SPA & SWE & U.K. & U.S. \\
\hline GDP growth & 2.57 & 2.08 & 2.49 & 2.00 & 2.01 & 1.83 & 2.93 & 2.11 & 2.01 & 2.59 \\
\hline Contribution \\
\hline TFP & 0.56 & 0.27 & 0.38 & -0.03 & -0.05 & -0.52 & -0.56 & -0.05 & -0.04 & -0.57 \\
\hline Capital & 0.59 & 0.32 & 0.74 & 0.65 & 0.63 & 0.63 & 1.31 & 0.81 & 0.74 & 1.09 \\
\hline ISTC (a+b) & 0.92 & 1.03 & 0.86 & 1.23 & 0.95 & 0.95 & 1.06 & 0.98 & 0.84 & 1.22 \\
\hline ICT (a) & 0.44 & 0.63 & 0.40 & 0.50 & 0.39 & 0.46 & 0.54 & 0.53 & 0.46 & 0.63 \\
\hline Non-ICT (b) & 0.48 & 0.40 & 0.46 & 0.72 & 0.56 & 0.49 & 0.52 & 0.45 & 0.38 & 0.59 \\
\hline Labor & 0.19 & 0.14 & -0.09 & -0.09 & 0.28 & 0.58 & 0.56 & 0.16 & 0.16 & 0.64 \\
\hline HCI & 0.31 & 0.32 & 0.60 & 0.24 & 0.20 & 0.19 & 0.57 & 0.21 & 0.31 & 0.21 \\
\hline Deci
\end{tabular}

Decomposition (\%)

\begin{tabular}{|l|c|c|c|c|c|c|c|c|c|c|}
\hline TFP & 21.6 & 13.1 & 15.1 & -1.3 & -2.5 & -28.5 & -19.2 & -2.2 & -2.2 & -21.8 \\
\hline Capital & 23.1 & 15.2 & 29.9 & 32.6 & 31.3 & 34.3 & 44.7 & 38.5 & 37.0 & 42.2 \\
\hline ISTC (a+b) & 35.7 & 49.6 & 34.4 & 61.3 & 47.4 & 51.9 & 36.2 & 46.3 & 41.9 & 46.9 \\
\hline ICT (a) & 17.1 & 30.5 & 16.0 & 25.2 & 19.6 & 24.9 & 18.4 & 25.0 & 22.8 & 24.3 \\
\hline Non-ICT (b) & 18.6 & 19.2 & 18.5 & 36.1 & 27.8 & 27.0 & 17.8 & 21.3 & 19.1 & 22.6 \\
\hline Labor & 7.5 & 6.6 & -3.6 & -4.7 & 13.9 & 31.7 & 19.1 & 7.4 & 7.9 & 24.7 \\
\hline HCI & 12.0 & 15.4 & 24.2 & 12.1 & 9.9 & 10.6 & 19.3 & 10.0 & 15.4 & 8.0 \\
\hline
\end{tabular}

\subsection{Results of the equilibrium growth accounting}

In this section, we focus on the determinants of labor productivity growth in the long run. For each country, we match the growth rate of productivity, ISTC, and HCI with their empirical counterparts and then we obtain the TFP as residual using equation (18) expressed in logarithmic terms, i.e.

$$
\gamma_{y / l}=\underbrace{\frac{\gamma_{A}^{G E}}{\alpha_{l}}}_{\text {TFP }}+\underbrace{\sum_{i} \frac{\alpha_{i}}{\alpha_{l}} \gamma_{i}}_{\text {ISTC }}+\underbrace{\gamma_{H}}_{H C I} .
$$

As mentioned in the Introduction, equation (21) illustrates that technological factors are the only determinants of economic growth in the long run. In Table 7, we report the relative importance of each factor in every country. Several results are worth emphasizing. First, the contribution of ISTC appears to dominate the contribution of both TFP and HCI. In the U.S., ISTC reaches its maximum relative contribution, explaining approximately $85 \%$ of long run growth. The contribution of neutral technical change in this country appears instead negative 
$(-5.3 \%)$. This result qualifies the one obtained by Greenwood et al. (1997), who attributed $58 \%$ of labor productivity growth to ISTC and $42 \%$ to neutral technical change. Three elements explain the differences between ours and their result. First, because TFP is computed residually, the inclusion of human capital progress in the analysis reduces the contribution of TFP with respect to that of Greenwood et al. (1997), who neglected this source of growth. Second, we use quality-adjusted prices for traditional assets, therefore employing a more accurate identification of ISTC, which according to Colecchia and Schreyer (2002), increases the relative contribution of ISTC to the detriment of TFP. Finally, and most importantly, a number of studies showed that the TFP process in the U.S. went flat along the postwar sample. According to Fernald (2012), the growth rate of TFP in the U.S. passed from a $2 \%$ average annual growth rate during the period 1948-1973 to less than $1 \%$ during the period 1984-2008. Hence, neutral technological progress surely explained a higher fraction of growth in the older sample (1954-1990) used in Greenwood et al. (1997).

Table 7. Equilibrium Decomposition of Labor Productivity Growth, 1980-2010

\begin{tabular}{|l|c|c|c|c|c|c|c|c|c|c|}
\hline & AUT & DEN & FIN & GER & ITA & NLD & SPA & SWE & U.K. & U.S. \\
\hline $\begin{array}{l}\text { Productivity } \\
\text { Growth }\end{array}$ & 2.28 & 1.88 & 2.62 & 2.14 & 1.59 & 0.96 & 2.05 & 1.88 & 1.79 & 1.60 \\
\hline Contribution & 0.82 & 0.29 & 0.79 & 0.40 & 0.21 & -0.39 & -0.01 & 0.48 & 0.44 & -0.08 \\
\hline TFP & 1.00 & 1.12 & 0.95 & 1.38 & 1.08 & 1.06 & 1.17 & 1.09 & 0.92 & 1.36 \\
\hline ISTC & 0.46 & 0.67 & 0.42 & 0.53 & 0.41 & 0.48 & 0.57 & 0.56 & 0.48 & 0.67 \\
\hline ICT & 0.54 & 0.45 & 0.53 & 0.85 & 0.67 & 0.58 & 0.60 & 0.52 & 0.44 & 0.69 \\
\hline Non-ICT & 0.46 & 0.47 & 0.88 & 0.36 & 0.30 & 0.29 & 0.89 & 0.31 & 0.43 & 0.32 \\
\hline HCI & 35.9 & 15.6 & 30.2 & 18.6 & 13.1 & -40.2 & -0.3 & 25.8 & 24.8 & -5.3 \\
\hline Decomposition (\%) & & & & \\
\hline TFP & 43.9 & 59.4 & 36.2 & 64.6 & 68.0 & 110.0 & 56.9 & 57.7 & 51.2 & 85.3 \\
\hline ISTC & 20.0 & 35.6 & 15.8 & 24.8 & 25.6 & 49.5 & 27.6 & 29.9 & 26.8 & 41.9 \\
\hline ICT & 23.9 & 23.8 & 20.3 & 39.8 & 42.4 & 60.4 & 29.3 & 27.8 & 24.4 & 43.4 \\
\hline Non-ICT & 20.2 & 25.0 & 33.6 & 16.8 & 18.9 & 30.2 & 43.4 & 16.5 & 24.0 & 20.0 \\
\hline HCI &
\end{tabular}

About the contribution of ISTC, its largest contributions are observed in Germany and the U.S., 1.38 and 1.36 percentage points on annual basis respectively, thus entailing a contribution to overall growth of $64 \%$ and $85 \%$. In the other countries the contributions of ISTC are very similar, approximately 1 percentage points on annual basis. The lowest value corresponds to the U.K. (0.92). This result is in line with Bakhshi and Larsen (2005), who found a similar result analyzing economic growth in U.K. during the period 1976-1998. Regarding the decomposition of ISTC between ICT and non-ICT technical change, we show that the contribution of technical change in traditional capital assets is similar to that of technical change in ICT despite the weight of ICT capital on total capital is sensibly smaller than that of non-ICT capital. This finding confirms the strong linkage between technical change in ICT capital and economic growth. More in details, the largest contribution of ICT- 
specific technical change corresponds to Denmark and the U.S. (0.67 percentage points in both cases), whereas the largest contribution of technological progress in non-ICT capital is observed in Germany ( 0.85 percentage points), followed by the U.S. ( 0.69 percentage points). Finally, we find that HCI contributes for approximately $0.3-0.4$ percentage points of growth in all countries except for Finland and Spain, where it contributed for, respectively, 0.88 and 0.89 percentage points. Overall, the results about HCI mirror those of the statistical growth accounting.

\section{Discussion}

Previous results from both the statistical and the equilibrium growth accounting analyses open to several considerations. We shall explore them in turn. First, the contribution of ISTC to economic growth appears highly sensitive to the statistical method employed. Jorgenson's method delivers roughly similar contributions across countries, approximately 0.50 percentage points, whereas Hulten's delivers much larger magnitudes and variability, with contributions ranging between 0.68 and 1.25 percentage points. In general, all methods arrive to similar results, indicating Germany and the U.S. as the largest ISTC innovators. In the first country, innovations predominantly affect traditional (non-ICT) capital assets, while in the second they mainly concern ICT. Also, we find that Finland and the U.K. are the countries in which ISTC contributed less regardless the method used. ${ }^{11}$ Overall, ISTC appears the main source of long run labor productivity growth in all of the considered countries. Only in Finland and Spain HCI yields comparable contributions accounting for almost as much GDP growth as ISTC.

Second, results on the contributions of neutral technical change are somewhat controversial. As expected, Solow's residual overstates the impact of TFP, whereas in Hulten's method it appears downward biased. In general, the only two countries in which the contributions of TFP are negative according to all methods are Spain and the Netherlands. In the economic literature, there is no widespread consensus on the interpretation of negative values of TFP (see Lipsey and Carlaw (2000) and references therein). If neutral technical change is intended to capture the effect of institutions and business organization on production, then negative growth rates of TFP should reflect the condition of mature developed economies in which infrastructures, institutions, and business organization are already at the technological frontier and can contribute no longer to economic growth. However, when assessing the role of TFP in growth accounting exercises it is compelling to use some precautions. First, it should be remarked that TFP is measured as a residual and therefore is subject to several sources of bias, e.g. (i) measurement errors in the data, (ii) interactions among heterogeneous sources of technical change that mask the true technical change processes (Schmitt-Grohe and Uribe (2011), Molinari, Rodriguez-Lopez and Torres (2013)), (iii) misspecifications in the theory used to derive the weights of factors-embodied technical change. This last element appears particularly insightful in the light of our results because the contributions of both TFP and ISTC turn out to be highly sensitive to the accounting method used, thus suggesting that the

11 This finding on the U.K. is in line with the results of Bakhshi and Larsen (2005). 
different assumptions used by Hulten and Jorgenson for the weight of ISTC crucially drives the results. Second, it should be noted that the relative price of investment is a suitable candidate to identify the process of ISTC only if neutral technical change affects the different industrial sectors with the same intensity. If this condition is violated, then the growth accounting procedure yields biased contributions of both ISTC and TFP. To cope with all these issues, it is advisable to focus the analysis on relative comparisons among countries rather than the level of contributions. In fact, because we use the same data source for all countries, any bias in the analysis, although severe, nonetheless is homogeneous across countries and therefore does not invalidate relative comparisons. In this perspective, one result that especially stands out in the analysis is the negative contribution of TFP in Spain and the Netherlands, because is robust to all methods employed, and because the contribution of TFP in the two countries is significantly lower than the sample average. Regarding the Netherlands, this finding is consistent with the analysis of TFP performed in Coe et al. (2008). Regarding Spain, our intuition suggests that this result may be driven by the highest rate of factors accumulation observed in this country, which are determined by the process of economic convergence that in the case of Spain overlaps with our sample period. Because these weights are proportionally related with the weights of ISTC and HCI, then any bias in the contributions of these two factors is maximized in Spain, thus reducing the contribution of TFP.

As final remark, it is worth noting that in the cross-country analysis, the contribution of TFP appears independent from the intensity of either ISTC or HCI. In particular, we find no evidence that the relative contribution of TFP depends on whether the country is an intensive user of ICT assets. According to our analysis, relatively similar countries in terms of ICT such as the U.K. or the U.S. show significant differences in TFP. This result appears to dismiss the findings of Jorgenson and Stiroh (2000) and Jorgenson (2001), who related the increase in U.S. productivity since mid-1990s to the increased growth rate of investment in ICT. As a matter of fact, Colecchia and Schreyer (2002), Daveri (2002) and Vijselaar and Albers (2002) also showed that ICT is not growth-enhancing in a number of countries with low ICT investment, in line with the results obtained in this paper. However, we do find an ordinate pattern between TFP and ICT when looking at the time dimension of the data. In those countries showing high ICT growth rates, we observe a strong negative correlation between the growth rates of ICT and that of TFP. A natural interpretation of this finding hinges on the considerable adjustment costs in terms of output arising when ICT equipment is adopted in business practice (Samaniego 2006). As argued by Lipsey et al. (1998): "By managing information flows more effectively than did the old, hierarchically organized, mass of middle managers, computers are causing major reorganizations in the management of firms". It is conceivable that during the transition firm's efficiency is considerably reduced.

\section{Conclusions}

In this paper we analyzed the relative importance of different types of technological progress, including human capital accumulation, as determinants of productivity growth in Europe and the U.S. Two different approaches have been employed in the analysis: traditional-statistical growth accounting and general equilibrium productivity growth decomposition. The 
first approach is implemented by using Solow's, Jorgenson's, and Hulten's growth accounting equations and focuses on the impact of physical capital and human capital in the short-run. The second approach is implemented by developing a variant of the neoclassical growth model and focuses on the determinants of labor productivity growth in the long run. Our results indicate that ISTC is the single most important source of long run growth in all of the considered countries, whereas contribution from TFP and human capital accumulation are of play a more limited role. In the short run, the single most important source of growth is capital accumulation in all countries but Denmark, where technical change in ICT assets plays the central role. This result is in part explained by the high share of investment in ICT assets observed in the Danish economy which, in fact, is the only European country with a share of ICT capital comparable with that the U.S. In general, we find that European countries still lag behind the U.S. regarding the growth-points contribution of ISTC except in the case of Germany, where technical change in traditional capital assets is great enough to compensate for the reduced observed technical change rate in ICT assets in this economy.

In the long-run, on average, more than $50 \%$ of productivity growth is explained by ISTC, whereas TFP growth and human capital accumulation account for the rest half. Nevertheless, the relative contribution from these last two technological changes varies significantly across countries. Interestingly, the contributions to growth from ICT and non-ICT assets technical change are of similar magnitude for all countries, indicating that not only ICT technological change but also traditional capital assets technological change are behind sustained productivity growth in the long-run. As a final remark, it should be noted that our analysis does not include possible cross-correlation effects between different sources of growth in the shortrun. These effects could be quantitatively important. We leave this issue to future research.

\section{Acknowledgements}

We gratefully acknowledge A. Bongers, J. Rodríguez, G. Fernández-de-Córdoba and Beatriz de Blas for their helpful comments and suggestions. José L. Torres acknowledges financial support from Proyecto Excelencia Junta de Andalucía P07-SEJ-02479 and SEJ-122. Benedetto Molinari acknowledges financial support from Proyecto Excelencia Junta de Andalucía SEJ1512. Corresponding author: José L. Torres, Department of Economics, University of Málaga, Campus El Ejido, s/n, 29013 Málaga (Spain), e-mail: jtorres@uma.es.

\section{References}

Aghion, P.; Howitt, P. 2005. Growth with quality-improving innovations: an integrated framework, in Handbook of Economic Growth, vol. 1. Elsevier, 67-110.

https://doi.org/10.1016/s1574-0684(05)01002-6

Ark, B. van; Inklaar, R.; McGuckin, R. 2003. ICT and productivity in Europe and the United States. Where do the differences came from?, in The Conference Board and Growth and Development Center of the University of Groningen, Economics Program Working Paper Series (EPWP), 03-05.

Bakhshi, H.; Larsen, J. 2005. ICT-specific technological progress in the United Kingdom, Journal of Macroeconomics 27(4): 648-669. https://doi.org/10.1016/j.jmacro.2004.03.004 
Coe, D.; Helpman, E.; Hoffmaister, A. 2008. International R\&D Spillovers and Institutions. IMF Working Paper, WP/08/104.

Colecchia, A.; Schreyer, P. 2002. ICT investment and economic growth in the 1990's: is the United States a unique case? A comparative study of nine OECD countries, Review of Economic Dynamics 5(2): 408-442. https://doi.org/10.1006/redy.2002.0170

Cummins, J. G.; Violante, G. L. 2002. Investment-specific technical change in the U.S. (1947-2000): measurement and macroeconomic consequences, Review of Economic Dynamics 5(2): 243-284. https://doi.org/10.1006/redy.2002.0168

Daveri, F. 2002. The new economy in Europe, 1992-2001, Oxford Review of Economic Policy 18(3): 345-362. https://doi.org/10.1093/oxrep/18.3.345

De Jong, D. N.; Ingram, B. F. 2001. The cyclical behavior of skill acquisition, Review of Economic Dynamics 4(4): 536-561. https://doi.org/10.1006/redy.2000.0124

Fernald, J. G. 2012. A quarterly, utilization-adjusted series on total factor productivity. Federal Reserve Bank of San Francisco. Working Paper, 2012-09.

Frantzen, D. 2000. R\&D, human capital and international technology spillovers: a cross-country analysis, The Scandinavian Journal of Economics 102(1): 57-75. https://doi.org/10.1111/1467-9442.00184

Gollin, D. 2002. Getting income shares right, Journal of Political Economy 110(2): 458-474. https://doi.org/10.1086/338747

Gort, M.; Greenwood, J.; Rupert, P. 1999. Measuring the rate of technological progress in structures, Review of Economic Dynamics 2(2): 207-230. https://doi.org/10.1006/redy.1998.0046

Greenwood, J.; Krusell, P. 2007. Growth accounting with investment-specific technological progress: a discussion of two approaches, Journal of Monetary Economics 54(4): 1300-1310. https://doi.org/10.1016/j.jmoneco.2006.02.008

Greenwood, J.; Hercowitz, Z.; Krusell, P. 1997. Long-run implication of investment-specific technological change, American Economic Review 87(3): 342-362.

Hercowitz, Z. 1998. The 'embodiment' controversy: a review essay, Journal of Monetary Economics 41(1): 217-224. https://doi.org/10.1016/S0304-3932(97)00065-2

Hulten, C. 1992. Growth accounting when technical change is embodied in capital, American Economic Review 82(4): 964-980. http://www.jstor.org/stable/2117353

Jalava, J.; Pohjola, M. 2002. Economic growth in the new economy: evidence from advanced economies, Information Economics and Policy 14(2): 189-210. https://doi.org/10.1016/s0167-6245(01)00066-X

Jorgenson, D. W. 1966. The embodiment hypothesis, The Journal of Political Economy 74(1): 1-17. https://doi.org/10.1086/259105

Jorgenson, D. W. 2001. Information technology and the U.S. economy, American Economic Review 91(1): 1-32. https://doi.org/10.1257/aer.91.1.1

Jorgenson, D. W.; Ho, M. S.; Stiroh, K. J. 2005. Growth of U.S. industries and investments in information technology and higher education, in NBER volume: C. Corrado, J. Haltiwanger, D. Sichel (Eds.). Measuring capital in the new economy. University of Chicago Press.

Jorgenson, D. W.; Stiroh, K. J. 2000. Raising the speed limit: U.S. economic growth in the information age, Brooking Papers on Economic Activity 1: 125-211. https://doi.org/10.1353/eca.2000.0008

Jorgenson, D. W.; Gollop, F. M.; Fraumeni, B. M. 1987. Productivity and U.S. economic growth. Cambridge: Harvard University Press.

Lipsey, R. G.; Bekar, C.; Carlaw, K. 1998. What requires explanation?, in E. Helpman (Ed.). General purpose technology and economic growth. MIT Press.

Lipsey, R. G.; Carlaw, K. 2000. What does total factor productivity measure?, International Productivity Monitor, 1 (Fall), unabridged version. 
Lucas, R. E. 1988. On the mechanics of economic growth, Journal of Monetary Economics 22(1): 3-42. https://doi.org/10.1016/0304-3932(88)90168-7

Melnikas, B. 2010. Sustainable development and creation of knowledge economy: the new theoretical approach, Technological and Economic Development of Economy 16(3): 516-540. https://doi.org/10.3846/tede.2010.32

Molinari, B.; Rodriguez-Lopez, J.; Torres, J. L. 2013. Information and communication technology over the business cycle, B.E. Journal of Macroeconomics 13(1): 933-963. https://doi.org/10.1515/bejm-2013-0064

OECD. 2001. Measuring capital. A manual on the measurement of capital stocks, consumption of fixed capital and capital services. Paris, OECD.

Oliner, S.; Sichel, D. 2000. The resurgence of growth in the late 1990s: is information technology the story?, Journal of Economic Perspectives 14(4): 3-22. https://doi.org/10.1257/jep.14.4.3

Oliner, S.; Sichel, D. 2003. Information technology and productivity: where are we now and where are we going?, Journal of Policy Modeling 25(5): 477-503. https://doi.org/10.1016/s0161-8938(03)00042-5

Oulton, N. 2007. Investment-specific technological change and growth accounting, Journal of Monetary Economics 54(4): 1290-1299. https://doi.org/10.1016/j.jmoneco.2006.02.004

Rodríguez, J.; Torres, J. L. 2012. Technological sources of productivity growth in Germany, Japan, and the United States, Macroeconomic Dynamics 16(1): 133-150. https://doi.org/10.1017/S1365100510000489

Samaniego, R. M. 2006. Organizational capital, technology adoption and the productivity slowdown, Journal of Monetary Economics 53(7): 1555-1569. https://doi.org/10.1016/j.jmoneco.2005.06.002

Schmitt-Grohe, S.; Uribe, M. 2011. Business cycles with a common trend in neutral and investmentspecific productivity, Review of Economic Dynamics 14(1): 122-135.

https://doi.org/10.1016/j.red.2010.07.001

Schreyer, P. 2002. Computer price indices and international growth and productivity comparisons, Review of Income and Wealth 48(1): 15-31. https://doi.org/10.1111/1475-4991.00038

Solow, R. 1956. A contribution to the theory of economic growth, Quarterly Journal of Economics 70(1): 65-94. https://doi.org/10.2307/1884513

Solow, R. 1957. Technical change and the aggregate production function, Review of Economics and Statistics 39(3): 312-320. https://doi.org/10.2307/1926047

Stiroh, K. 2002. Information technology and U.S. productivity revival: what do the industry data say?, American Economic Review 92(5): 1559-1576. https://doi.org/10.1257/000282802762024638

Timmer, M.; van Ark, B. 2005. Does information and communication technology drive EU-U.S. productivity growth differentials?, Oxford Economic Papers 57(4): 693-716.

https://doi.org/10.1093/oep/gpi032

Uzawa, H. 1965. Optimum technical change in an aggregative model of economic growth, International Economic Review 6(1): 18-31. https://doi.org/10.2307/2525621

Vijselaar, F. W.; Albers, R. M. 2002. New technologies and productivity growth in the Euro area. ECB Working Papers No. 122. 